ISSN 2179-345X

Licenciado sob uma Licença Creative Commons

(c) (i)

\title{
O princípio da proibição do retrocesso socioambiental e o "novo" Código Florestal
}

\author{
The principle of prohibition of environmental \\ retrogression and the "new" Forest Code
}

\author{
Euseli dos Santos
}

Mestrando em Direito, como aluno especial, pela Universidade Metodista de Piracicaba (Unimep), advogado, Uberaba, MG - Brasil, e-mail: euseli@terra.com.br

\section{Resumo}

A evolução do pensamento ecológico após a crise ambiental enfrentada nos períodos subsequentes à Segunda Grande Guerra criou um ambiente propício ao surgimento do Direito Ambiental. Uma série de manifestações em âmbito internacional alarmaram os Estados sobre os problemas decorrentes da exploração desenfreada dos bens ambientais, o que culminou na constitucionalização, em diversos países, de normas de proteção ao meio ambiente. No Brasil, a Constituição Federal de 1988 positivou no art. 225 uma série de 
dispositivos que trouxeram normatização inédita em matéria ambiental, dentre os quais a garantia do direito fundamental ao meio ambiente ecologicamente equilibrado, um dos mais maciços pilares sobre os quais se sustenta a tutela jurídica do meio ambiente no Direito brasileiro, e o dever Estatal de proteção do meio ambiente. Essa tutela ambiental constitucional, cumulada com a celebração de tratados e convenções internacionais que visam à promoção e aperfeiçoamento da proteção ecológica permitiram dizer que o Brasil adotou o princípio da vedação do retrocesso socioambiental, que consiste, em suma, na proibição de abolição da proteção ambiental já consagrada no ordenamento jurídico em detrimento dos direitos fundamentais dos cidadãos. A revogação do Código Florestal pela Lei n. 12.671/2012, que alterou sensivelmente o tratamento ecológico das reservas ambientais e Áreas de Proteção Permanente, dentre outras modificações que se contrapõem aos fundamentos constitucionais da tutela ambiental adotados em nosso país, tem gerado profundas discussões doutrinárias, o que foi o objeto do presente estudo.

Palavras-chave: Meio ambiente. Direito fundamental. Proibição de retrocesso. "Novo" Código Florestal.

\section{Abstract}

The evolution of ecological thinking following the environmental crisis faced in periods subsequent to the Second World War created a favorable context to the emergence of environmental law. A series of manifestations at the international level the States alarmed about the problems arising from unbridled exploitation of environmental goods, which culminated in Constitutionalisation, in many countries, of rules of environmental protection. In Brazil, the Federal Constitution of 1988 legalized in art. 225 a series of devices that have brought unprecedented environmental regulation, among them the guarantee of a fundamental right to an ecologically balanced environment, one of the most solid pillars on which sustains the legal protection of the environment in the Brazilian Law and duty State protection of the environment. This constitutional environmental protection, combined with the conclusion of international treaties and conventions aimed at promoting and enhancing the ecological protection allowed to say that Brazil adopted the principle of prohibition of environmental retrogression, which consists, in short, the prohibition of the abolition of environmental protection already enshrined in law at the expense of the fundamental rights of citizens. The repeal of the Forest Code by the Law 12.671/2012,

Rev. Direito Econ. Socioambiental, Curitiba, v. 3, n. 2, p. 505-529, jul./dez. 2012 
which significantly altered the ecological treatment of environmental reserves and areas of permanent protection, among other modifications that are opposed to the fundamentals of environmental protection adopted in our country has generated deep doctrinal discussions, which was the object of this study.

Keywords: Environment. Fundamental rights. Prohibition of retrogression. "New" Forest Code.

\section{Introdução}

O Direito Constitucional, notadamente na Teoria dos Direitos Fundamentais, tem caminhado no sentido de evolução e aprimoramentos constantes. As diversas alterações na realidade global, aliadas à necessidade de adaptação às novas exigências sociais, transformam os textos das constituições em autênticas construções abertas, que necessitam da mudança para permanecerem vivas.

Sob essa visão, considerando os valores impulsionados pelas relações sociais, especialmente em âmbito internacional a partir dos anos 1970, é possível constatar uma marcante presença das manifestações em prol da defesa do meio ambiente e da melhoria da qualidade de vida dos indivíduos, por força da crise ambiental eclodida no período imediatamente após a Segunda Grande Guerra.

Esses novos valores modificaram e vêm ainda influenciando a cultura jurídica nos mais diversos países. O resultado disso foi uma densificação da proteção ao meio ambiente por meio da criação de novas leis. Aliada a esse fenômeno, notadamente após a Convenção de Estocolmo, tem se notado uma massiva introdução dos direitos ambientais nos textos das constituições nacionais, na maioria dos casos sob a forma de direito fundamental, que passa a emanar a sua normatividade dentro dos ordenamentos.

No Brasil, a Constituição Federal de 1988, ao afirmar e garantir o direito fundamental a um meio ambiente ecologicamente equilibrado e 
ratificar o princípio da dignidade humana como um dos fundamentos da República, eleva a proteção ambiental a um novo patamar.

O presente estudo, por meio de pesquisa exploratória e bibliográfica e da utilização do método indutivo, visou a explicitar as linhas básicas do princípio da proibição do retrocesso, segundo o qual a tutela ecológica sempre deve ser progressiva e se aperfeiçoar, jamais retrocedendo nos níveis do já citado âmbito de proteção. Nesse aspecto, abordou-se o caso específico do "novo" Código Florestal brasileiro, sancionado parcialmente em março de 2012, e os principais aspectos das alterações por ele introduzidas, no que tange à qualidade da proteção ambiental dispensada.

\section{O amadurecimento do pensamento ecológico e o surgimento do Direito Ambiental}

É impossível aferir de forma exata há quantos anos surgiu a espécie humana. Apesar disso, é certo que a relação da nossa espécie com a natureza confunde-se com a própria história das sociedades.

Os povos da Antiguidade começaram a valorizar as terras que eram banhadas pelos rios, pois, com o transbordamento, os húmus adubavam as margens, tornando-as mais férteis para a plantação. Eles instalavam-se e edificavam em torno dos rios e suas vidas obedeciam ao regime das regas, passando a se adequar às variáveis dos cursos d'água (SIRVINSKAS, 2012, p. 83). Nesse ponto da história, em que pesem as crenças religiosas tribais ligadas aos elementos da natureza, não se vislumbra na organização das sociedades uma preocupação no sentido de preservar os recursos ambientais, pelo menos do ponto de vista jurídico.

Essa constatação é, no mínimo, compreensível: os recursos naturais nos momentos mais primitivos da espécie humana eram abundantes. Não havia qualquer conflitualidade no que tange à apropriação desses bens e sua exploração não refletia de forma negativa na qualidade de vida dos indivíduos. Esse panorama passou por uma drástica alteração durante o caminhar das civilizações, notadamente após a primeira revolução 
industrial e a Segunda Grande Guerra (MCNEILL apud CANOTILHO; LEITE, 2012, p. 79).

No transcorrer dos últimos três séculos se intensificou o fenômeno econômico segundo o qual as necessidades humanas são múltiplas, correntes e ilimitadas, enquanto os bens naturais são, por definição, limitados (MILARÉ, 2011, p. 65). Isso reflete de forma mais ou menos enfática grande parte dos conflitos ambientais que, em um primeiro momento, passaram a surgir em decorrência da escassez de bens naturais - as dissensões em busca do controle de elementos essenciais para o desenvolvimento econômico dos países e das indústrias.

Sob uma visão mais aguçada, a tomada de consciência da crise ambiental é deflagrada, principalmente, a partir da constatação de que as condições tecnológicas, industriais e formas de organização e gestão econômicas da sociedade estão em conflito com a qualidade de vida dos indivíduos, sobretudo com a coligação do intenso crescimento demográfico ocorrido nos séculos XIX e XX (LEITE; AYALA, 2012, p. 25).

\footnotetext{
Verifica-se que tanto as ideologias liberais como as socialistas não souberam lidar com a crise ambiental, considerando que o capitalismo industrialista, no primeiro caso, e o coletivismo industrialista, no segundo, puseram em prática um modelo industrial agressivo aos valores ambientais da comunidade. Essencialmente, a crise ambiental configura-se no esgotamento dos modelos de desenvolvimento econômico e industrial experimentados. De fato, o modelo proveniente da revolução industrial, que prometia o bem-estar para todos, não cumpriu aquilo que prometeu, pois apesar dos benefícios tecnológicos, trouxe principalmente, em seu bojo, a devastação ambiental planetária e indiscriminada (LEITE; AYALA, 2012, p. 26).
}

O primeiro grande alerta sobre os riscos do desenvolvimento econômico desenfreado foi dado em 1972, em Estocolmo, na Conferência das Nações Unidas sobre o Meio Ambiente Humano. "A conferência resultou na percepção das nações ricas e industrializadas a respeito da degradação 
ambiental causada pelo seu modelo de crescimento econômico que acarretou progressiva escassez de recursos naturais" (MILARÉ, 2011, p. 66).

Esse antagonismo entre os sistemas econômicos e a falência do modelo estatal alheio às questões ambientais fizeram indagar sobre as propostas e alternativas que poderiam ser colocadas diante dos problemas apresentados.

Uma das soluções apontadas e que recebeu grande aceitação no cenário nacional e internacional é a proposta de implementação do "desenvolvimento sustentável", ou "durável", para o qual se deve satisfazer as necessidades do presente sem colocar em risco a capacidade das gerações futuras de terem suas próprias necessidades satisfeitas.

Apesar das dificuldades práticas e críticas à probabilidade de alcance de um pleno "desenvolvimento sustentável", não se pode negar que a formação de uma nova consciência ecológica refletiu de forma intensa no direito dos mais diversos países, em muitos casos, com a massificação da proteção ambiental nas legislações. No Brasil, por exemplo, foi promulgada a Lei da Política Nacional do Meio Ambiente em 1981 e a Lei da Ação Civil Pública em 1985. Nesse momento histórico, para Antunes (2012, p. 15):

o desenvolvimento brasileiro, como regra, sempre se fez com pouco respeito ao meio ambiente, pois calcado na exploração intensiva dos produtos primários com vistas ao mercado externo, sem qualquer preocupação mais profunda quanto à sua conservação. A partir da década de 80 do século XX, sobretudo após a edição da Lei da Política Nacional do Meio Ambiente, começou-se a se formar uma nova maneira de pensar as relações entre a atividade econômica e o meio ambiente. Isso se deu, principalmente, com a introdução do conceito de sustentabilidade e da constatação de que os recursos naturais são finitos. Essa mudança de concepção, contudo, não é linear, e sem dúvida, podemos encontrar diversas contradições e dificuldades na implementação de políticas industriais que levem em conta o fator ambiental e que, mais do que isso, estejam preocupadas em assegurar a sustentabilidade de utilização de recursos ambientais. 
Essa "crise ambiental", como tem sido definida pelos autores, foi amplamente debatida no cenário internacional (VARELLA, 2004, p. 2147), destacando-se a Declaração de Estocolmo das Nações Unidas sobre Meio Ambiente Humano (1972), o Protocolo de San Salvador Adicional à Convenção Americana de Direitos Humanos em Matéria de Direitos Econômicos, Sociais e Culturais (1988), a Declaração do Rio de Janeiro sobre Meio Ambiente e Desenvolvimento (1992), a Convenção-Quadro das Nações Unidas sobre a Mudança de Clima (1992), a Declaração e Programa de Ação de Viena (1993), o Protocolo de Quioto (1997), a Convenção de Estocolmo sobre Poluentes Orgânicos (2001) e, mais recentemente, a Convenção das Nações Unidas sobre Desenvolvimento Sustentável - Rio+20 (2012).

As Constituições modernas foram amplamente influenciadas por essa nova noção ecológica. Os rumos das legislações constitucionais foram alterados por conta dos diversos compromissos assumidos pelos países em âmbito internacional.

Assim como outrora a Teoria da Constituição e o Direito Constitucional estiveram comprometidos na afirmação dos valores liberais e sociais (valores à agenda constitucional), hoje a proteção e promoção do ambiente desponta como valor constitucional, de forma que se poderia falar em um "esverdear" da ordem jurídica, mas especialmente da Teoria da Constituição e do Direito Constitucional (SARLET; FENSTERSEIFER, 2012, p. 26).

Sob esses fundamentos, as constituições passam a assegurar a proteção ambiental em seu bojo, conforme claramente se constata pela análise das constituições portuguesa (1976) e espanhola (1978), influenciadas pela Declaração de Estocolmo, da Lei Fundamental Alemã (1949, pela reforma de 1994), Constituição colombiana (1991), sul-africana (1996) e da Constituição suíça (2000).

Recentemente, isso ocorreu com a Constituição francesa (1958, por meio da incorporação constitucional da Carta do Meio Ambiente de 2004), a Constituição equatoriana (2008) e a Constituição boliviana (2009) (SARLET; FENSTERSEIFER, 2012, p. 27-28), o que refletiu a 
crescente preocupação das sociedades com a proteção ao meio ambiente e preservação dos recursos naturais.

A ecologização da constituição não é cria tardia de um lento e gradual amadurecimento do Direito Ambiental [...]. Muito ao contrário, o meio ambiente ingressa no ambiente constitucional em pleno período de formação do Direito Ambiental. A experimentação jurídico-ecológica empolgou, simultaneamente, o legislador infraconstitucional e constitucional (CANOTILHO; LEITE, 2012, p. 84).

A partir de uma sistemática normativa constitucional, que estabelece os pilares básicos sobre os quais se funda o Direito Ambiental dentro dos países, pode-se seguir uma linha teórica coerente para melhor proteção do meio ambiente e preservação da qualidade de vida humana, o que justifica o estudo e a menção ao Direito Comparado em âmbito legal e constitucional.

\section{A constitucionalização do Direito Ambiental no Brasil: o direito fundamental ao meio ambiente ecologicamente equilibrado e o dever de proteção do Estado}

O Brasil, atento à crise ambiental que se instala, não seguiu caminho diferente dentro desse "esverdear" das Constituições. A Constituição da República Federativa do Brasil de 1988 dedicou um importante tópico ao meio ambiente: o Capítulo VI do Título VII, sobre a "ordem social". Os dispositivos constantes dessa passagem fazem, ainda, referência explícita ou implícita a outras normas constitucionais, impondo que haja um estudo sistemático do Direito do meio ambiente dentro de nossa Carta Magna.

Apesar da existência de um único artigo no Título da Ordem Social, por meio do art. 225, nota-se ampla normatização da questão em âmbito constitucional. Para Silva (2011, p. 54), é possível destacar três conjuntos de normas diferentes dentro do dispositivo. A primeira delas é encontrada no caput, em que é prevista a norma-matriz, que substancialmente revela o direito de todos ao meio ambiente ecologicamente equilibrado.

Rev. Direito Econ. Socioambiental, Curitiba, v. 3, n. 2, p. 505-529, jul./dez. 2012 
O segundo grupo encontra-se no $\S 1^{\circ}$ e seus incisos, que prescrevem os instrumentos de garantia da efetividade do direito anunciado no caput. "Mas não se trata de normas simplesmente processuais, meramente formais. Nelas, aspectos normativos integradores do princípio revelado no caput se manifestam através de sua instrumentalidade" (SILVA, 2011, p. 54), especialmente por meio da outorga de direitos e imposição de deveres.

E o terceiro, finalmente, constitui-se de um conjunto de determinações a grupos particulares, em relação a objetos e setores, referidos $\operatorname{nos} \S 2^{\circ}$ a $6^{\circ}$. Para Antunes (2012, p. 61),

a Constituição Federal de 1988, como tem sido amplamente sublinhado pelos constitucionalistas, trouxe imensas novidades em relação às cartas que a antecederam, notadamente na defesa dos direitos e garantias individuais e no reconhecimento de uma nova gama de direitos, dentre os quais se destaca o meio ambiente. As Leis Fundamentais anteriores não se dedicaram ao tema de forma abrangente e completa: as referências aos recursos ambientais eram feitas de maneira esparsa e não sistemática, com pequenas menções aqui e ali, sem que se pudesse falar na existência de um contexto constitucional de proteção ao meio ambiente. Os constituintes anteriores a 1988 não se preocuparam com a conservação dos recursos naturais ou com a sua utilização de forma racional.

Nesse viés, é importante verificar que "a Constituição Federal de 1988 sepultou o paradigma liberal que via (e insiste em ver) no direito apenas um instrumento de organização da vida econômica, unicamente orientando a resguardar certas liberdades básicas e a produção econômica" (CANOTILHO; LEITE, 2012, p. 104).

O reconhecimento jurídico expresso do meio ambiente no patamar constitucional dá amparo a uma percepção ampliada do Direito Ambiental, que se valoriza em um ponto de vista individual e social.

A afirmação do direito ao meio ambiente ecologicamente equilibrado coloca o homem no centro do pensamento ecológico, assegurando a exigibilidade material e subjetiva dessa garantia a partir dos 
instrumentos próprios de implementação dos direitos fundamentais, também previstos constitucionalmente.

O caput do art. 225 da Carta Magna, ao estabelecer que "todos têm direito ao meio ambiente ecologicamente equilibrado, bem de uso comum do povo e essencial à sadia qualidade de vida, impondo-se ao Poder Público e à coletividade o dever de defendê-lo e preservá-lo para as presentes e futuras gerações", vai muito além das dimensões econômicas liberais, ou mesmo sociais, para adentrar o novo paradigma do Estado democrático de Direito instaurado a partir do advento da Constituição.

Para Silva (2011, p. 711) o grande avanço proporcionado pelo moderno capítulo do meio ambiente, o que é também afirmado por Canotilho e Leite (2012, p. 106), é: "de toda sorte [...] a face mais visível de um regime constitucional que, em vários pontos, dedica-se direta ou indiretamente, à gestão dos recursos ambientais".

Para Sampaio (2004, p. 25-28), os direitos fundamentais estão sempre ligados à noção de direitos humanos básicos do indivíduo. Sob um ponto de vista dogmático, poder-se-ia falar em um núcleo de direitos e garantias axiologicamente afetados como indispensáveis à vida humana.

Do ponto de vista formal, "os direitos fundamentais são aqueles reconhecidos na Constituição ou em tratados internacionais" (FAVOREU, 1998, p. 780 apud CANOTILHO; LEITE, 2012, p. 116), que atribuem ao indivíduo garantia subjetiva ou pessoal e são representativos de valores objetivos de atuação e compreensão do ordenamento jurídico.

Significa dizer que a aceitação de um determinado direito como fundamental possibilita que o cidadão exija a tomada de comportamentos positivos ou negativos para o cumprimento daquele direito. Além disso, determina a necessidade de o Estado efetivar o Direito positivado, que passa a irradiar sua normatividade para todo o ordenamento jurídico constitucional e infraconstitucional, em suas funções de produção, interpretação e aplicação - um autêntico dever de proteção.

Por tais razões, parece correto afirmar que todos os direitos fundamentais (na sua perspectiva objetiva) são sempre, também, direitos 
transindividuais. É neste sentido que se justifica a afirmação de que a perspectiva objetiva dos direitos fundamentais não só legitima restrições aos direitos subjetivos individuais com base no interesse comunitário prevalente, mas também que, de certa forma, contribui para a limitação do conteúdo e do alcance dos direitos fundamentais, ainda que deva sempre ficar preservado o núcleo essencial destes (SARLET, 2007, p. 171).

Há consenso entre os juristas no que tange ao reconhecimento da existência de um direito fundamental ao meio ambiente ecologicamente equilibrado, especialmente nos países que modificaram suas Constituições após a Conferência de Estocolmo, formando um dos novos direitos fundamentais. Apesar disso, há alguns desencontros teóricos no que tange à sua natureza axiológica:

na doutrina, a valoração dogmática desse direito não é uniforme. Alguns o consideram um direito da personalidade e, simultaneamente, como um direito e uma garantia constitucional, ou seja, direito fundamental na visão da Constituição de 1988 e direito da personalidade, na perspectiva do Direito Privado. Outros o reputam, simultaneamente, direito e princípio, ou, ainda, encarnação de direito humano ou direito subjetivo ao meio ambiente ecologicamente equilibrado (CANOTILHO; LEITE, 2012, p. 117).

Em que pesem essas divergências, é comum entre todas essas teorias o enquadramento desse direito no plano mais elevado do caderno de direitos reconhecidos aos cidadãos. Por tal razão, Sarlet e Fensterseifer (2012, p. 36) ressaltam que a positivação do direito fundamental ao meio ambiente nos remete à já citada interdependência entre o ser humano e a natureza, dentro desse panorama de adequação aos enfrentamentos postos pela crise ecológica, o que constitui um aspecto central da política-jurídica ambiental contemporânea.

Sob outro aspecto, cumpre salientar que o direito previsto no caput do art. 225 tem sido enquadrado dentre aqueles "novos" direitos fundamentais denominados de terceira geração, coletivos, ou de grupos, 
fundados na solidariedade (VARELLA, 2004, p. 293), e que dependem fortemente de mecanismos de cooperação substancial de todas as forças sociais para sua realização:

os novos direitos se definem na medida em que eles são novos nas aspirações que expressam, são novos na dimensão humana em áreas onde ela tem sido frequentemente esquecida, tendo sido deixada para o Estado ou Estados... Eles são novos na medida em que podem simultaneamente ser invocados contra o Estado e exigidos deste; mas acima de tudo (e aqui reside a sua característica essência), eles só podem ser realizados por meio de esforços conjuntos de todos os atores da cena social: o indivíduo e o Estado, corporações públicas e privadas e a comunidade internacional (BOSSELMANN, 1998, p. 293-294 apud SARLET; FENSTERSEIFER, 2012, p. 37).

Assim, percebe-se que o direito fundamental ao meio ambiente protege, sobretudo, os fundamentos do desenvolvimento da vida sob um ponto de vista que transcende os interesses da pessoa humana, enfatizando um sentido que não se associa ao objeto de proteção de posições jurídicas particulares, mas comunitárias e fundadas na solidariedade (AYALA, 2011, p. 243).

Essas sustentações teóricas nos permitem dizer que, ao mesmo tempo em que esse direito pode ser exigido, tem também de ser protegido pelo Estado e pela sociedade para assegurar a manutenção da qualidade do meio ambiente garantida constitucionalmente.

A Constituição da República Federativa do Brasil de 1988, ao seguir a influência do Direito Constitucional contemporâneo e do Direito Internacional, sedimentou os alicerces normativos de um constitucionalismo ecológico (SARLET; FENSTERSEIFER, 2012, p. 40) e garantiu aos cidadãos o direito de viver em um meio ambiente saudável, o que obriga o Estado e a sociedade a zelar por esse direito fundamental.

Ajustada à evolução no âmbito do direito constitucional comparado registrada na última quadra do século XX, especialmente por força da 
influência do ordenamento internacional (onde se consolidou todo um conjunto de convenções e declarações em matéria de proteção ambiental), a CF/88 consagrou em capítulo próprio (art. 225), o direito ao ambiente ecologicamente equilibrado como direito (e dever!) fundamental da pessoa humana e estabeleceu um conjunto de princípios e regras em matéria de tutela ambiental, reconhecendo o caráter vital da qualidade (e segurança) ambiental para o desenvolvimento humano em níveis compatíveis com sua dignidade, no sentido da garantia e promoção de um completo bem-estar existencial (SARLET; FENSTERSEIFER, 2012, p. 186).

Dessa forma, a Constituição, além de elevar o meio ambiente ao status de direito fundamental, ainda consagrou a proteção ambiental como um dos objetivos ou tarefas primordiais do Estado, reconhecendo a dupla função do instituto, o que impõe a obrigação constitucional de adoção de todas as medidas legislativas e administrativas atinentes à tutela ecológica, de forma a assegurar o adequado gozo desse direito.

Para Silva (2011, p. 77), a repartição de competências em matéria ambiental no Brasil segue os mesmos princípios adotados para a distribuição entre os entes federativos. União, Estados, municípios e Distrito Federal têm competência para a proteção ambiental.

Apesar dessa distribuição, o art. 225 impõe ao Poder Público de forma genérica o dever de defender e preservar o meio ambiente para as presentes e futuras gerações, com a incumbência de tomar todas as providências indicadas nos incisos do $\S 1^{\circ}$ do mesmo artigo, para assegurar a efetividade do direito de todos ao meio ambiente ecologicamente equilibrado.

Nessa perspectiva, os deveres de proteção no âmbito do Estado constitucional se fundamentam no compromisso constitucional assumido pelos entes estatais, no sentido de tutelar e garantir nada menos do que uma vida digna e saudável aos indivíduos e grupos sociais. Isso passa pela tarefa de promover a realização dos seus direitos fundamentais, retirando possíveis óbices colocados à sua efetivação, inclusive por meio de ações positivas estatais, que possibilitem a remoção de obstáculos de 
ordem econômica, social e cultural, impedindo o pleno desenvolvimento da pessoa humana (LUÑO, 2005, p. 214).

Sob a perspectiva da dimensão objetiva dos direitos fundamentais, pode-se afirmar que a proteção ambiental deve ser alçada ao plano de valor jurídico do Estado, o que impõe, de imediato, que os princípios e valores ambientais sejam tomados como bens jurídicos fundamentais, projetando-se na aplicação e concretização do direito e na tutela por meio de normas penais, civis, processuais e administrativas, dentre outras, e no controle e fiscalização do cumprimento dos referidos diplomas.

Outro aspecto importante atrelado aos deveres de proteção ambiental do Estado diz respeito à limitação da discricionariedade estatal (legislativa, administrativa e judicial) deles decorrente. Os deveres de proteção ambiental conferidos ao Estado vinculam os poderes estatais ao ponto de limitar a sua liberdade de conformação na adoção de medidas atinentes à tutela do meio ambiente [...]. Em outras palavras, pode-se dizer que - na perspectiva dos deveres de proteção e do dever de proteção suficiente que lhes é correlato - tanto não há "margem" para o Estado não atuar, quanto não lhe é deferida a prerrogativa de "atuar de forma insuficiente" (tudo à luz do princípio da proibição ou de insuficiência de proteção ou de proteção deficiente, aqui vislumbrado, em especial, na sua conexão com as exigências da proporcionalidade) na proteção do ambiente, pois tal atitude estatal resultaria em prática inconstitucional (SARLET; FENSTERSEIFER, 2012, p. 188).

O Estado, então, a depender do caso concreto, deve adotar condutas positivas ou negativas buscando potencializar ao máximo a proteção ambiental no âmbito das funções e dos entes estatais. Dessa forma, "o atual projeto normativo-constitucional do Estado (socioambiental!) de Direito brasileiro, delineado pela Lei Fundamental de 1988, conforma um Estado 'guardião e amigo' dos direitos fundamentais" (SARLET; FENSTERSEIFER, 2012, p. 192), de forma que todos os poderes e órgãos se encontram vinculados às diretrizes ecológicas constitucionais. 


\section{O princípio da proibição do retrocesso socioambiental e o "novo" Código Florestal}

Conforme já apontado, a evolução do pensamento ecológico no decorrer do século XX culminou, no Brasil, no reconhecimento do direito fundamental a um meio ambiente ecologicamente equilibrado e na constitucionalização da tutela ambiental a partir de uma série de princípios e regras voltados para a manutenção da qualidade do meio ambiente em níveis compatíveis com a dignidade humana e com o pleno desenvolvimento do indivíduo.

Em um contexto mais amplo, nota-se que os direitos humanos como um todo passaram por esse processo de evolução no decorrer dos tempos, notadamente em virtude das diversas manifestações na comunidade internacional, e passaram a ser admitidos nos ordenamentos positivos nacionais pela sua constitucionalização ${ }^{1}$.

Por essa razão, para Sarlet e Fensterseifer (2012, p. 196), é possível dizer que "a humanidade caminha na perspectiva de ampliação e salvaguarda da dignidade da pessoa humana, conformando a ideia de um 'patrimônio político-jurídico' consolidado ao longo do seu percurso histórico-civilizatório, para aquém do qual não se deve retroceder".

Por isso, para Barroso (2001, p. 158), pelo princípio da vedação ao retrocesso "que não é expresso, mas decorrente do sistema jurídico constitucional, entende-se que se uma lei, ao regulamentar um mandamento constitucional, instituir determinado direito, ele se incorpora ao patrimônio jurídico da cidadania e não pode ser absolutamente suprimido".

A proibição do retrocesso se fundamenta no princípio da segurança jurídica e em seus respectivos desdobramentos (proteção da confiança pelo direito adquirido, ato jurídico perfeito e coisa julgada), guardando conexão com os limites materiais a emendas constitucionais, uma

1 Para maiores desenvolvimentos, ver a obra de Comparato (2010): A afirmação histórica dos direitos humanos. 
vez que tais institutos também guardam relação com a proibição de atos e medidas de caráter retroativo que venham, de algum modo, a afetar situações e posições jurídicas consolidadas.

Nesse cenário, diz respeito mais especificamente a uma garantia de proteção dos direitos fundamentais (e da própria dignidade da pessoa humana) contra a atuação do legislador, tanto no âmbito constitucional quanto - e de modo especial - infraconstitucional (quando estão em causa medidas legislativas que impliquem supressão ou restrição no plano das garantias e dos níveis de tutela dos direitos já existentes), mas também proteção em face da atuação da administração pública. A proibição do retrocesso, de acordo com o entendimento consolidado na doutrina, consiste em um princípio constitucional implícito, tendo como fundamento constitucional, entre outros, o princípio da dignidade da pessoa humana, o princípio da máxima eficácia e efetividade das normas definidoras de direitos fundamentais, o princípio da segurança jurídica e seus desdobramentos, o dever de progressividade dos direitos sociais, econômicos, culturais e ambientais, apenas para citar os mais relevantes fundamentos jurídico-constitucionais invocados (SARLET; FENSTERSEIFER, 2012, p. 197).

Quer dizer o autor que a tutela constitucional do meio ambiente é direito fundamental do cidadão e que, além de integrar um núcleo intangível por modificações restritivas por emenda constitucional (cláusula pétrea), não pode sofrer retroação por parte de alterações na legislação infraconstitucional integrativas da proteção dispensada pelo texto constitucional, sob pena de retrocesso ambiental e consequente inconstitucionalidade.

Constata-se, dessa forma, que a proibição de retrocesso se expressa a partir da ideia de proteção dos direitos fundamentais, especialmente no que tange ao seu núcleo essencial, na medida em que a tutela e o exercício efetivo de tais direitos só são possíveis onde esteja assegurado um nível mínimo de segurança jurídica e previsibilidade do próprio ordenamento jurídico objetivo, bem como dos direitos subjetivos dos cidadãos. 
Por força do art. $5^{\circ}, \S 1^{\circ}$ da nossa Lei fundamental, é imposta a proteção efetiva dos direitos fundamentais não apenas contra a atuação do poder de reforma constitucional (em combinação com o art. 60, que dispõe a respeito dos limites formais e materiais às emendas constitucionais), mas também contra o legislador ordinário e os demais órgãos estatais (em vista de que medidas administrativas e decisões jurisdicionais também podem atentar contra a segurança jurídica e a proteção da confiança), os quais são incumbidos de um dever permanente de desenvolvimento e concretização dos direitos fundamentais, o que não permite, em qualquer hipótese, a supressão ou restrição desses de modo a invadir o seu núcleo essencial, bem como, atentar, de outro modo, às exigências do princípio da proporcionalidade (SARLET; FENSTERSEIFER, 2012, p. 202).

Essa perspectiva só é reforçada a partir do ponto de vista do Direito Internacional e da cláusula de progressividade ou dever de progressiva realização e proteção, que é prevista no Pacto Internacional dos Direitos Econômicos, Sociais e Culturais, de 1966, que impõe que os Estados pactuantes implementem de forma progressiva os direitos sociais neles consagrados; na Convenção Americana sobre Direitos Humanos, de 1969, e pelo Protocolo de San Salvador, que contém a chamada "proibição de retrocesso social".

Nesse viés, para Sarlet e Fensterseifer (2012, p. 203), a cláusula de progressividade veicula a necessidade de a tutela legislativa a determinado direito fundamental ser permanentemente aprimorada e fortificada, contendo dois conteúdos normativos. O primeiro consiste em "não piorar" a situação jurídica do cidadão diante daquele direito fundamental; e o segundo consiste na obrigação de "melhorar", ou seja, de aprimorar as condições normativas e fáticas e assegurar um contexto cada vez mais favorável ao desfrute de uma vida digna.

Assim sendo, mostra-se mais adequado do ponto de vista da Teoria dos Direitos Fundamentais, e também do Direito Internacional dos Direitos Humanos, o tratamento integrado e interdependente entre 
os direitos sociais e ecológicos, de modo a comtemplar a evolução histórica dos direitos fundamentais e humanos, já citada anteriormente.

Aliás, o próprio texto do Protocolo de San Salvador já previa que "toda pessoa tem direito a viver em um ambiente sadio e a contar com os serviços públicos básicos", bem como que "os Estados-Partes promoverão a proteção e melhoramento do meio ambiente", diretriz que já fora esboçada no Pacto Internacional de Direitos Econômicos, Sociais e Culturais de 1966 (PACTO INTERNACIONAL, 2012).

Dessa forma, a cláusula de progressividade "atribuída aos direitos sociais deve abarcar, necessariamente, também as medidas normativas voltadas à tutela ecológica, de modo a instituir uma progressiva melhoria na qualidade ambiental, e consequentemente, na qualidade de vida geral" (SARLET; FENSTERSEIFER, 2012, p. 204), sendo possível concluir pela adoção no ordenamento jurídico brasileiro da cláusula de vedação do retrocesso aos direitos fundamentais em geral, contemplando também a vedação ao retrocesso socioambiental.

A tutela ecológica, tanto constitucional quando infraconstitucional (que em verdade complementa os princípios e regras dispostos na Lei fundamental, integrando-se a ela), não podem sofrer modificações que resultem no retrocesso da proteção dispensada ao meio ambiente, que é direito fundamental dos cidadãos e uma das feições da dignidade da pessoa humana.

Em todo esse contexto, em que se defende sempre a evolução dos direitos fundamentais dos indivíduos e a máxima proteção ao patrimônio jurídico do cidadão, salvaguardado pela Constituição Federal e pelo Direito Internacional, o Poder Público parece ter dado longos passos em direção contrária, apesar de sua incumbência constitucional de defesa e preservação do meio ambiente.

Em virtude da sanção ao PL n. 1.876/1999 pela presidenta Dilma Rousseff (acompanhada do veto parcial de 12 dispositivos do texto original), no dia 25 de maio de 2012, o texto parcialmente aprovado deu origem à Lei n. 12.651/2012, com a redação que lhe foi também atribuída 
pela MP n. 571/2012, que revogou o Código Florestal Brasileiro (Lei n. 4.771/1965) e "reforçou um cenário de transformações legislativas que colocam o Direito ambiental brasileiro em um novo, perigoso e indesejável défices de proteção, oriundo do contexto de retrocessos normativos e institucionais em curso" (LEITE; AYALA, 2012, p. 371).

Para Leite e Ayala (2012, p. 372), os 12 vetos veiculados pela Presidenta não foram capazes de permitir que o texto do "novo Código Florestal" continuasse a colaborar com a proteção de funções ecológicas de espaços e de recursos naturais e, principalmente, com a garantia da viabilidade da vida, por meio da proteção de processos ecológicos essenciais.

O "novo Código Florestal" sugere variados graus de flexibilização na proteção dos espaços ou dos recursos que se encontravam protegidos originalmente pela Lei n. 4.771/65, e propõe desde a diminuição da proteção até a eliminação da proteção que antes se encontrava assegurada pelo Código Florestal.

As afirmações podem ser demonstradas e já o foram por meio de evidências por expressivas instituições brasileiras (IBGE, INPE, IBAMA E IPEA), as quais alertaram desde o ano de 2008 para um quadro que exigiria atenção especial de todos os poderes públicos, sobre a particularidade das fontes nacionais de emissão de gases efeito-estufa (apenas para citar a maior fonte de ameaças à biodiversidade, que pode ser favorecida pelo novo texto sancionado pela presidente Dilma Roussef) (LEITE; AYALA, 2012, p. 373).

Para Leite e Ayala (2012, p. 374) é importante consignar que as Áreas de Preservação Permanente e reserva legal (que parecem ter perdido a função ecológica no novo texto) constituem importantes instrumentos não apenas para a estabilidade do clima, e para viabilizar o desenvolvimento da vida, senão de garantia da própria atividade econômica.

No mesmo sentido, a concessão de anistia, ou desoneração do dever de recuperar as áreas de reserva legal degradadas, já teve o seu efeito avaliado pelo Instituto Nacional de Pesquisas Espaciais (Inpe), 
estimando-se a perda de 79 milhões de hectares degradados em todo o território nacional ${ }^{2}$.

A emissão desmedida de gás carbônico, consequência de um desmatamento desmesurado do cerrado e da floresta amazônica para a expansão da pecuária e agricultura em largas escalas, passa a preocupar ainda mais a partir da sanção da lei em comento, cenário que já vinha se agravando desde a proteção normativa do revogado Código Florestal, que era mais ampla e efetiva que o da nova lei.

Seria possível dizer que a Lei n. 12.651/12 comprometeu severamente a viabilidade de oferecer proteção normativa a cada um daqueles bens e espaços naturais, surgindo como prognóstico uma grave distorção que poderá se fixar no sistema de responsabilidade civil ambiental. Prejudicou-se, assim, a proteção ecológica como um todo, em evidente retrocesso ambiental.

Um Código Florestal que não consegue demonstrar sua capacidade de proteger as pessoas e os processos ecológicos essenciais para que a vida possa se desenvolver, e que não consegue veicular uma relação de indivisibilidade entre as liberdades econômicas e a conservação dos recursos naturais, propõe de forma ostensiva, que os recursos naturais não poderão ser explorados de forma duradoura (LEITE; AYALA, 2012, p. 376).

Dessa forma, se o Poder Legislativo propõe normatização que não consegue proteger os cidadãos e o meio ambiente, propiciando o exercício da atividade econômica, essa normatização, seguramente, não tem qualquer condição de viabilizar um modelo viável e factível de desenvolvimento, que neste momento exige a consolidação de um sentido de durabilidade e de permanência, combinado com a garantia da qualidade de vida digna.

Por isso é que, para Leite e Ayala (2012, p. 376), "ganha ênfase a consideração de uma obrigação normativa de progressividade, e de um

2 Informações do Comunicado 96 do Inpe, quando se tinha em questão a aprovação da primeira versão do Código na Câmara dos Deputados. INSTITUTO DE PESQUISA ECONÔMICA APLICADA IPEA. Código florestal: implicações do PL n. 1876/99 nas áreas de reserva legal. Brasília: IPEA, 2011. 
imperativo de não retorno nos níveis de proteção". Apesar dos vetos, a consideração conjunta do dispositivo do "novo" Código Florestal aponta para um retrocesso da proteção ecológica, o que já era apontado pela doutrina antes mesmo da aprovação do projeto:

as razões para manter o Código Florestal Brasileiro com o padrão normativo (no sentido da tutela do ambiente) a atualmente vigente são muitas - tanto a partir de uma abordagem social e ecológica, quanto pelo prisma de uma perspectiva econômica -, ao passo que, do outro lado, as razões para se endossarem as mudanças afunilam-se no interesse - puramente econômico e exclusivo - do setor agropecuário. O descaso do projeto de lei com a qualidade e o equilíbrio ecológico é gritante, alinhando-se a isso também todos os aspectos sociais e econômicos vinculados à degradação ecológica (SARLET; FENSTERSEIFER, 2012, p. 223).

Conforme já fora exposto, o ordenamento jurídico brasileiro, que incorpora os tratados e convenções celebrados no âmbito internacional, e a própria Constituição da República não se mostram tolerantes com comportamentos que violem o patamar mínimo de proteção ambiental já consagrado pelas normas adotadas.

A Constituição brasileira exige que o Estado e toda a comunidade política protejam os processos ecológicos essenciais e se abstenham de realizar escolhas que ameacem as funções ecológicas da flora e da fauna (art. 225, 1이 I e VII), definindo ainda a proteção daqueles fundamentos naturais indispensáveis ao desenvolvimento da vida e no interesse das gerações futuras.

Por tal razão, quando se parte para a análise do novo Código Florestal em face da garantia constitucional da proibição do retrocesso socioambiental, toda teia normativa de proteção dos direitos fundamentais faz peso no sentido da inconstitucionalidade das "flexibilizações" legislativas que comprometeram a proteção anteriormente dispensada ao meio ambiente.

Sendo assim, as escolhas legislativas "não podem, desse modo, atingir os limites que definiriam um mínimo existencial ecológico (art. 225, inciso I), ao mesmo tempo em que devem ser capazes de aperfeiçoar os 
níveis já atingidos no interesse das futuras gerações" (art. 225, caput) (LEITE, AYALA, 2012, p. 377).

Constata-se então que, em uma realidade, como a que foi descrita, a sanção parcial da Lei n. 12.651/2012 ao propor a diminuição nos níveis de proteção dos bens ambientais expõe visivelmente uma realidade por meio da qual a Constituição brasileira e o próprio Estado de direito não são respeitados. Não é admissível a desconstrução de todo um sistema de proteção ambiental, com amparo constitucional, em prol dos interesses de grupos específicos, ocasionando retrocesso ecológico e a não observância dos princípios elementares do Direito Ambiental, notadamente a vedação ao retrocesso socioambiental.

\section{Considerações finais}

Por tudo que foi exposto, percebe-se que a discussão acerca da adoção de um princípio da vedação do retrocesso socioambiental no ordenamento jurídico brasileiro pode ser concluída com a constatação de fundamentos legais e constitucionais que permitem sua plena aplicação.

É evidente que, pelos tratados e convenções internacionais aos quais o Brasil se submete e pelo contexto da tutela ambiental na Constituição Federal de 1988, existe um mínimo existencial ecológico e que a proteção ao meio ambiente dispensada constitucionalmente e integrada pela legislação infraconstitucional não pode ser suprimida em detrimento dos direitos fundamentais dos cidadãos.

Nesse contexto, insere-se o emblemático caso do "novo" Código Florestal brasileiro. Sua aprovação e sanção parcial representou, para o ordenamento ambiental, um evidente favorecimento indevido ao setor agropecuário.

A diminuição da proteção ambiental que era dispensada pelo revogado Código às Áreas de Preservação Permanente e reserva ambiental, dentre outras, foi sensivelmente afetada pelo novo texto, o que representa um retrocesso ecológico incompatível com o regime adotado pela 
Constituição da República, no que concerne à tutela do meio ambiente e dos direitos fundamentais.

\section{Referências}

ANTUNES, P. B. Direito ambiental. 14. ed. São Paulo: Atlas, 2010.

AYALA, P. A. Devido processo ambiental e o direito fundamental ao meio ambiente. Rio de Janeiro: Lumen Juris, 2011.

BARROSO, L. R. 0 direito constitucional e a efetividade de suas normas. 5. ed. Rio de Janeiro: Renovar, 2001.

BRASIL. Presidência da República. Lei n. 4.771, de 15 de setembro de 1965. Institui o novo Código Florestal. Diário Oficial [da] República Federativa do Brasil, Poder Legislativo, Brasília, DF, 15 set. 1965. Disponível em: <http:// www.mp.go.gov.br/portalweb/hp/9/docs/14771.pdf>. Acesso em: 23 dez. 2011.

BRASIL. Constituição (1988). Constituição: República Federativa do Brasil. Brasília, DF: Senado Federal, 1988.

BRASIL. Câmara dos Deputados. Projeto de Lei n. 1.876 de 19 de outubro de 1999. Dispõe sobre Áreas de Preservação Permanente, Reserva Legal, exploração florestal e dá outras providências. Brasília, DF, 19 out. 1999. Disponível em: <http://www.camara.gov.br/proposicoesWeb/fichadetramitacao?idProposic ao=17338 $>$. Acesso em: $23 \mathrm{dez} .2011$.

BRASIL. Presidência da República. Lei n. 12.651, de 25 de maio de 2012. Dispõe sobre a proteção da vegetação nativa; altera as Leis n. 6.938, de 31 de agosto de 1981, 9.393, de 19 de dezembro de 1996, e 11.428, de 22 de dezembro de 2006; revoga as Leis n. 4.771, de 15 de setembro de 1965, e 7.754, de 14 de abril de 1989, e a Medida Provisória n. 2.166-67, de 24 de agosto de 2001; e dá outras providências. Diário Oficial [da] República Federativa do Brasil, Poder Legislativo, Brasília, DF, 25 maio 2022. Disponível em: <http://www.planalto.gov.br/ccivil_03/_Ato2011-2014/2012/Lei/L12651.htm>. Acesso em: 23 dez. 2011. 
CANOTILHO, J. G.; LEITE, J. R. M. Direito constitucional ambiental brasileiro. 4. ed. São Paulo: Saraiva, 2011.

COMPARATO, F. K. A afirmação histórica dos direitos humanos. 7. ed. São Paulo: Saraiva, 2010.

INSTITUTO DE PESQUISA ECONÔMICA APLICADA - IPEA. Código Florestal: implicações do PL 1876/99 nas áreas de reserva legal. Brasília: IPEA, 2011.

LEITE, J. R. M.; AYALA, P. A. Dano ambiental: do individual ao coletivo extrapatrimonial. 5. ed. São Paulo: Revista dos Tribunais, 2012.

LUÑO, A. P. Los derechos fundamentales. 8. ed. Madrid: Tecnos, 2005.

MILARÉ, É. Direito do meio ambiente: a gestão ambiental em foco. 7. ed. São Paulo: Revista dos Tribunais, 2011.

PACTO INTERNACIONAL dos direitos econômicos, sociais e culturais (1966). Disponível em: <http://www.pge.sp.gov.br/centrodeestudos/bibliotecavirtual/ instrumentos/direitos.htm>. Acesso em: 28 dez. 2011.

SAMPAIO, J. A. L. Direitos fundamentais: retórica e historicidade. Belo Horizonte: Del Rey, 2004.

SARLET, I. W. As dimensões da dignidade da pessoa humana: construindo uma compreensão jurídico-constitucional necessária e possível. Revista Brasileira de Direito Constitucional, v. 9, p. 361-388, 2007.

SARLET, I. W.; FENSTERSEIFER, T. Direito constitucional ambiental: constituição, direitos fundamentais e proteção do ambiente. 2. ed. São Paulo: Revista dos Tribunais, 2012.

SILVA, J. A. da. Direito ambiental constitucional. 9. ed. São Paulo: Malheiros, 2011.

SIRVINSKAS, L. P. Manual de direito ambiental. 10. ed. São Paulo: Saraiva, 2012.

Rev. Direito Econ. Socioambiental, Curitiba, v. 3, n. 2, p. 505-529, jul./dez. 2012 
VARELLA, M. D. Direito internacional econômico ambiental. Belo Horizonte: Del Rey, 2003.

Recebido: 02/08/2011

Received: 08/02/2011

Aprovado: $12 / 07 / 2012$

Approved: 07/12/2012 